\title{
Uncertainty in pediatric bone marrow transplantation: A qualitative analysis about parents' perspective
}

\author{
Bernardi Matteo ${ }^{* 1}$, Martina Ceron ${ }^{2}$ \\ ${ }^{1}$ Pediatric Department of Padua Hospital, Padua, Italy \\ ${ }^{2}$ Padua University, Padua, Italy
}

Received: June 7, 2015

Accepted: October 12, $2015 \quad$ Online Published: October 25, 2015

DOI: $10.5430 /$ jnep.v6n1p111

URL: http://dx.doi.org/10.5430/jnep.v6n1p111

\begin{abstract}
Background: The uncertainty is innate in parents of children under bone marrow trasplantation. The parents' view of uncertainty during their children's bone marrow transplantation (TCSE) hasn't yet been explored. There is evidence that uncertainty experienced as a reaction to disease is linked to a lower quality of life. The purpose of this study was to explore the parents' experience of uncertainty during their children's TCSE.

Methods: This study applied qualitative approach using phenomenology method. To perform this qualitative study, semistructured interviews were performed. Basing on this analysis, we will evaluate if Mishel's Uncertainty in Illness Theory can explain this experience and specify the connection between uncertainty experienced by family and nursing care during TCSE. A convenience sample of 26 parents were recruited from TCSE unit in Padua Hospital. Each interview was audio recorded, transcribed, and coded for major theme using a content analysis approach. The extracted interviews were analyzed through Colaizzi method. Interview topics were: uncertainty aspects during bone marrow transplantation, means of uncertainty, life aspects influenced by uncertainty, how dealt with uncertainty.

Results: From the analysis of the interviews four macro categories were defined: multiple uncertainty's meanings, multiple side of uncertainty, uncertainty side effects, management of uncertainty. The parents will live the consequences of such uncertainty for all their life and they will never find a boundary which lay the end. The bone marrow transplantation doesn't remove uncertainty, but it causes uncertainty. Parents report need for contact with expert nurses to discuss the meaning of their uncertainty, in order to reduce it.

Conclusions: The parents' experience of uncertainty can be described following Mishel's Uncertainty in Illness Theory. The lives of the parents are dominated by uncertainty. Nurses need to be educated to be able to encourage parents to communicate their existential questions and the impact of the illness on their life. Enhanced awareness and increased understanding about parents' uncertainty can be important factors in improving nursing work environment and the quality of care presented to pediatric patients and their family.
\end{abstract}

Key Words: Uncertainty, Nursing, Pediatric bone marrow transplantation, Parent impact, Phenomenology

\section{INTRODUCTION}

Blood and marrow transplant (BMT) offers children with life-threatening illness, and their families, hope of durable cure when no other curative treatment is available. ${ }^{[1]}$ However parents of children undergoing BMT often experience a great deal of stress and are at risk for short and long-term psychosocial sequelae, such as depression, anxiety and decrease quality of life. ${ }^{[2-5]}$

Enhancing our understanding of the parent, family, and BMT

*Correspondence: Bernardi Matteo; Email: matteo.bernardi@ sanita.padova.it; Address: Pediatric Department of Padua Hospital, Padua, Italy. 
characteristics that are associated with increased parental impact may help clinicians identify parents most at risk, and lead to the development of interventions to support parents through the BMT trajectory. In one study of 49 parents/guardians of BMT recipients, $81 \%$ of parents/guardians reported they felt proceeding to BMT was their only choice, given its life-saving potential. ${ }^{[6]}$ Because of the high stakes and demands of the treatment, support for these potentially vulnerable parent caregivers is paramount. ${ }^{[5]}$

At the Oncoematology wards uncertainty is innate in parents of children under treatment, even though it is rarely disclosed with questions and puzzlements regarding the need of undergoing a transplant, the phases to be faced, the evolution post-transplant. ${ }^{[7]}$ Parents may remain apprehensive about their child's health and well-being long after the successful treatment of cancer, reflecting uncertainty about current $\mathrm{e}$ future health. ${ }^{[8-10]}$

Uncertainty is a pervasive experience and a major psychological stressor that affect many aspects of live with a major impact on patients' illnesses. Uncertainty is a multifaceted concept, and its understanding for patients and their parents depends on many factors. ${ }^{[11]}$

Mishel $(1988,1990)^{[12,13]}$ presented a nursing theory of uncertainty in illness from both a theoretical and an empirical perspective, defined as the inability to determine the meaning of illness-related events.

Uncertainty has long been recognized as a significant issue in paediatric oncology patients. It emerges as a major source of distress in interviews with parents of children with cancer. ${ }^{[14]}$

The parents' experience of uncertainty during their children's bone marrow transplantation (TCSE) hasn't yet been explored, thus leaving a gap in the scientific debate. In the literature investigations can be found regarding the uncertainty experienced by parents' of children facing a relapse: they bounce between hope and fear, hope for a definitive healing on one side, fear for the possible loss of their children on the other. ${ }^{[15-17]}$

A few works have investigated the relation between uncertainty and Post Traumatic Stress Disorder (PTSD) in parents during their children's disease course. ${ }^{[16,17]}$ Some others have considered PTSD in parents in relation with their children's bone marrow transplantation: it was assessed that uncertainty levels and PTSD are directly connected. ${ }^{[17-19]}$

It is in this scenario of uncertainty that the nurse operates. Nurses have most frequent contact with patients and their family, they are in the best position to reduce uncertainty by providing information, improving the patients' perception of health and preserving hope, as well as being aware of the need to view the patients' health status in a positive manner. ${ }^{[20]}$ Therefore, it is vital for nurses to understand the interactive, collaborative nature of uncertainty management.

In this research, we are going to explain the life experiences of parents' bone marrow recipients to help these family by use of its results.

There is growing consensus that the needs, preferences and experiences of patients should receive more consideration in the development as well as the evaluation of new health technologies or service delivery models and that this approach should be extended to health technology assessment and systematic reviews. ${ }^{[7,21]}$ Uncertainty is a dynamic phenomenon and different perspectives must be applied to achieve a fuller understanding. ${ }^{[22]}$ Therefore, the focus of this study is analyzing parents' live experiences exploring the role of uncertainty during bone marrow transplantation from nursing perspective.

\section{METHODS}

\subsection{Purpose}

The purpose of this study was to explore the parents' experience of uncertainty during their children's TCSE and to gain understanding of nursing intervention that may decrease uncertainty in this kind of population. Basing on this analysis, we will evaluate if Mishel's Uncertainty in Illness Theory can describe this experience and specify the connection between uncertainty experienced by family and nursing care during TCSE.

This study applied qualitative approach using phenomenology method to explain the life experience of parents who care children during bone marrow transplantation. Phenomenology research helps to describe the experiences and phenomenon as they experienced. ${ }^{[23]}$

\subsection{Study participants}

The sample involved was composed of 26 parents (aged 2452 years) whose 26 children (aged 3-16 years) had had a bone marrow transplantation at the Oncoematology pediatric ward in Padua, from July 2012 through August 2013 (see Table 1).

Inclusion criteria for parents were: ability to speak/ understand Italian, parent of the BMT patient. Participation was left voluntary and all participants were informed of the focus of the research, the nature of their involvement, the required time to complete the interview and confidentiality of data. They were then asked to provide written informed consent and permission to record the interview. All record, tapes, and transcripts were kept confidential. The study was approved by the appropriate university, which supervised the study and corroborated its ethical considerations.

ISSN 1925-4040 E-ISSN 1925-4059 
Table 1. Characteristics of study participants $(\mathrm{N}=26)$

\begin{tabular}{lll}
\hline Characteristic & Child N (\%) & Parents N (\%) \\
\hline Age in years (Mean \pm SD) & $9.8 \pm 6$ & $40.8 \pm 10.5$ \\
Female vs. Male & $15(58)$ & $22(85)$ \\
Education (high scholl graduate-college graduate) & $/$ & $10(39)-6(23)$ \\
Race/Ethnicity & & $19(73)$ \\
Caucasian & $19(73)$ & $1(83.8)$ \\
Black & $1(3.8)$ & $5(19)$ \\
Hispanic & $5(19)$ & $1(83.8)$ \\
Asian & $1(3.8)$ & $/$ \\
Months following TCSE (mean) & 20 & \\
\hline
\end{tabular}

The survey's sample was made of 4 fathers and 22 mothers. Eight mothers have a nationality other then Italian, and five among them (one Ukrainian and five Venezuelans) came in Italy exclusively in pursuit of a cure for their children. Only one father is not Italian (Congolese nationality). Children's dates of birth and details regarding the transplants were obtained from medical records. Two children went through autologous transplant, while for the remaining the transplant was of allograft kind.

\subsection{Investigation method}

To perform this qualitative study, an semi-structured interview was performed. Audio-recorded, face-to-face, semistructured interviews lasting 20-45 minutes were held in quiet locations in the nursing wards convenient to the participants. The interviews were conducted by two authors of this study.

The interviews covered the parents' experiences about the uncertainty and strategies employed to encounter it in the care of their children during transplantat. Five questions were selected with Mishel's uncertainty method and literature research and submitted to each parent, given their written agreement and a privacy statement.

Submitted questions are the following:

(1) Can you describe, if any, some uncertainty aspects you had felt while your child was experiencing the transplant, from the diagnosis communication to the discharge?

(2) What did this uncertainty mean to you?

(3) Which aspects of your life had been influenced by the uncertainty you have experienced, from the diagnosis communication to the discharge?

(4) How had you dealt with uncertainty? What had helped you in reducing or controlling it?

(5) Could you talk about the moments when you had felt more uncertainty?
In addition, probing questions were asked to follow the participants' thoughts and bring clarification to the participants' responses during the interviews.

Each interview was recorded on the audio file and each interview wrote on the paper word-by-word after repeatedly listening, and coded for major theme using a content analysis approach. The analysis was conducted accordingly to seven stage Colaizzi method: ${ }^{[24]}$ during the first stage, versions of interview were studied carefully. During the second stage, important sentences and those related to the under study phenomenon underlined. During the third stage, the extracted meanings were conceptualized and formulated and initial codes extracted from underlined important sentences, which related to the under study phenomenon. During the fourth stage, after repeatedly reading and repeating the third stage, the formulated concepts organized in to categories and thematic clusters based on the common meanigs. During the fifth stage, the results of each cluster were gathered using comprehensive explanation of the under-study themes and bigger categories formed which were closer to the main concepts resulted from analysis the information. During the sixth stage, concepts resulted from the fifth stage were integrated and more general and abstract concepts formed and main concepts of research created.

Several experts in qualitative research controlled the project from the data collection through the final theme extraction. Moreover, the researchers frequently reviewed the interviews for conflicting aspects.

The data were coded and categorized independently by the authors of this study and then the last developments as themes were compared. In disagreement situations, discussions and clarifications continued until a consensus was achieved. In addition, a summary of the interviews was returned to the participants as member check and it was confirmed that the researcher was re-presenting their ideas and their real world. 


\section{RESULTS}

A total of 105 initial codes extracted by studying the written interviews and placed in the thematic categories and $17 \mathrm{~s}$ level main codes resulted from them. The bigger categories created and four main concepts of research formed; those themes and codes represent in Table 2.

Multiple meanings are the main concepts of research which resulted from the second level codes of fear, transplant out- comes, hope, awaiting and personal growth. Participant number 5 states: “ [...] When the doctors say you the transplant is the path to follow, you hope your child will heal, you hope once did the transplant, there will be no need for other treatments [...]. You should always hope! There's the question mark, but you should say: 'There must be a glimmer of light beyond the question mark', otherwise you don't wake up in the morning. You should always hope. Always."

Table 2. Themes which resulted from codes based on the Colaizzi analysis

\begin{tabular}{lll}
\hline Row & Codes & Themes \\
\hline & Fear & \\
Transplant outcomes & Multiple Meanings \\
Hope & Awaiting & \\
& Personal growth & \\
Feelings about transplant & Multiple side of uncertainty \\
& Life dilemma & Uncertainty side effects \\
& How to live & \\
& Sign of distress & \\
& Physical effects & \\
& Perspective of future & Management of uncertainty \\
& Relationship with other family/patients (second family) & \\
& My family & \\
& Sense of being grateful & \\
& Faith & \\
& Healthcare staff & \\
\hline
\end{tabular}

The mothers who come from South America and East Europe live a specific and different experience: uncertainty is connected with awaiting. When I asked to a mother the meaning she had given to uncertainty, she says: "Now I cannot live without that halo of anguish".

At the end, there are mothers who consider uncertainty as an experience of personal growth. A mother states: "It was an experience that made grow up me, my daughter and all those who were with me. I could consider this path as a growth, as a way of seeing life and the things around me differently [...]. You test life in a different way, you enjoy it, you live it [...]. Uncertainties make me stronger [...]. It's an experience that scars you inside, outside, around: everywhere".

The second macro category include the "multiple sides of uncertainty". This theme resulted from the second level codes of Feelings about transplant and emotional experiences.

Over time this feeling has assumed a number of shades of fear and anxiety. In the following bit of interview, a mother describes her feelings regarding the transplant: "[...] At 3, 6,9 months after the transplant the bone marrow is checked:
I live that day with anxiety. Well, I live everyday with the urge of receiving answers. Since the transplant I live even worse!". Similarly, a mother says: "You're always waiting for answers". She concludes the interview stating: "[... ] I don't know the greater or lesser sense of uncertainty. Id est, it is constant all day long, day and night. Perhaps, it becomes greater little by little, because you become aware people you knew passed away. So you wonder: "And now whose is the turn? And now?"

A mother says uncertainty becomes lesser after the transplant " [...] Uncertainty is lesser, but you live always with anguish [...]". The third macro category consists in "the uncertainty side effects": experiencing the unknown for a long period of time marks the parents lives with an indelible scar, and it has collateral consequences on their relationships, for example the conjugal one and the one with the eventual healthy children. One mother states: "[...] My other child was often left home alone and could not understand what was happening [...]. He is now seeing the speech therapist and the psychiatrist because he was obviously touched by 
the experience, and still is".

Uncertainty has also side effects on the parents perspective of future. A mother admits: "I live day by day, step by step. I cannot make plans for the future. I cannot say "Next year I will do, I will leave for...". I live day by day, month by month". One mother, crying, says: “[... I I've lost my centre of gravity. I can't think of a future anymore. I don't feel like having a future anymore, I don't feel like planning for the long term because everything can bring me back here at anytime [...]. I don't have a tomorrow: I will wake up tomorrow morning and I will hope for the best!". In the following bit of interview, a mother states how in her life all collapsed: "You don't never give future to things around you to overcome well the day. However, we come into the world thinking about the future and this aspect becomes a contrast in our mind, because everything is based on the future".

Sometimes, the mother's body show the sign of distress; a psychologist said to a mother: "It is useless you go to the dermatologist. If you don' calm down... You are so anxious...!".

The fourth and last macro category consists in "the management of uncertainty". This is usually done thanks to the help of the family and other parents that are walking the same path. One mother describes: "[...] I could see the other parents, the ones who had been there before, their strength [...]". In the end they become part of your family. Many parents have claims that health personnel helped them to deal with uncertainty and they have been a reference point.

I can't tell you some children have no significance for me because now they are part of my family. The other children continue to be part of something that is inside you. When you see suffering you could become a "bear" or you could start to hope all children heal. For what it concerns her husband, a mother says: "[...] He was stronger than me [...]. He gave me strength: if I hadn't had him, I don't know how I would do at certain circumstances. Sometimes, You wonder: "Why it happened to us?"

\section{Discussion}

The lives of the parents are dominated by uncertainty that comes clearly out from the interviews. On this point, a mother revealed: "[...] Since we started this path, until this moment, we go ahead with a question mark. Always. No one knows something. Every day you live step by step; you live always with a question mark and with the uncertainty of not knowing how far you get and what you will find. Not knowing when everything would be finished and how it would be finished don't make feel you steady: it's like being on a boat in the middle of the sea (..) $[. .$.$] ".$

Published by Sciedu Press
Uncertainty is reflected in mothers and fathers' fear, the fear of losing their child, despite the transplant: "[...] The other fears you feel in the life are fears you find a solution to: they may be terrible, but you are there and you are able to deal with them [...]. The fear of my daughter's death is still inside me. I think it will take years before that fear steps: it is a constant anguish".

The parents will live the consequences of such uncertainty for all their life and they will never find a boundary which lay the end Parents' experience could be explained by Mishel's theory ${ }^{[13,19,25,26]}$ in which uncertainty is the consequent of 3 variables: stimuli frame, cognitive capacity and structure providers.

In the "stimuli frame", pattern of symptoms coincides with a relapse: under certain circumstances, the parents' expectations fell short because they were told that bone marrow transplantation didn't lead to the desired outcomes. The second component of the variable is the event familiarity: the novelty of a situation for the parents - the transplant - arouses a greater level of uncertainty. The third element is the congruence of the event, which Mishel defined as "the congruence between what you expect and what you live during the illness". The parents saw the transplant as immediate healing, but nowadays they still live in waiting to know whether son in finally cured or not.

The stimuli frame is affected by two variables: the cognitive abilities (the ability the person has to process the information he receives) and the structure providers which are the resources the person uses to explain stimuli frame. The structure providers are represented by the level of education, credible authority and social support (other parents and the husband or the wife).

A form of social support has been found by parents to other parents who over time has become a sort of "second family" to whom face together the long and uphill path, the transplant. Actually, these human relationships, on the one hand, help these parents, on the other hand, they deeply destroy them because sometimes it means being spectators of an upcoming and personal future. At this juncture, the nurse must be able to mediate social support in order to avoid uncertainty become a danger for these mothers and fathers.

In parents' experience of uncertainty the nurse must become the credible authority for what it concerns the answers about the development of uncertainty that he gives and sustains during the transplant. He must be a referee for all the period of transplant (the support and preparation activities in the period before the transplant are important). The nurse is the credible authority for the parents who cannot find answers 
anywhere, nor by any other means. Nowadays, patients seek and find information about illnesses on internet; this cannot be said for aspects that relate to uncertainty experienced by parents. They could ask any questions about uncertainty only to nurses and they could find answers only in nurses.

The nurse must be able to develop in parents coping skills that allow them to consider uncertainty as an opportunity: only in this way he could help the parents to deal with uncertainty and manage it. Regarding cognitive ability and level of education, this study didn't give answers. Nurses must pay attention also to mothers who come from Latin America and Eastern Europe. The nurse must pay greater attention to the congruence of the event and social support in their lives. These women left their respective countries with uncertainty and expectations, since even for their children the bone marrow transplantation means healing and life. The art of nursing consists of expert use and adaptation of empirical knowledge and values. It involves sensitively adapting care to meet the needs of individual patients, and in the face of uncertainty, the discretionary use of creativity. ${ }^{[27]}$

\section{Conclusion}

The parents live in a state of uncertainty both before and after their children's bone marrow transplantation. This uncertainty hasn't a time limit but it will last over time.

The bone marrow transplantation doesn't remove uncertainty, but it causes uncertainty. A father said: "[...] I think by now we have uncertainty inside. I don't know when we will able to remove it. I think it will never happen". If the nurse doesn't intervene since the beginning of hospitalization in transplant center and doesn't reduce parents' uncertainty, the illness may take on the features of a chronic illness and may protract over the years and be accompanied to psychological repercussions (such as anguish, distress, anxiety) on parents and their son. Moreover, the child may become a chronic patient.
Actually, the nurse isn't aware of uncertainty that rouses those psychological problems. Nowadays, the nurse doesn't realize neither how much uncertainty affects parents' and their son's future life, nor how much he concretely could do. The nurse should choose to become aware of the uncertainty the parents feel, otherwise this state could lead to psychological problems in both parents and children, such as anxiety and distress. The nurse should try to give to parents' uncertainties an answer because the bone marrow transplantation represents a starting point and doesn't represent the goal.

It is important to provide insights into the aspects of uncertainty and to be sensitive. Providing clear and accurate information when requested, being supportive and allowing patients to discuss the meaning of their uncertainty is all essential. Further studies are needed on caring interventions that facilitate communication about what matters to patients and their families in order to guide nursing practice.

Research in the nursing and midwifery disciplines has been both patient- and theory-oriented in order to achieve evidence-based practice, thereby improving the quality of care. For this reason it is necessary to explore various patientoriented phenomena. Collaboration and continuity between patients, families and professionals are crucial for ongoing support.

The results of this research ca be used in an educational, research and clinical field. In addition, further studies should substantiate our study findings and develop a model about the domains and elements of uncertainty in children bone marrow transplantation using an in-depth qualitative research approach such as grounded theory. The transferability of the findings should be considered after testing their applicability in other cultures and contexts. However, it is believed that the results are innovative and noteworthy despite the limitation.

\section{CONFlicts OF INTEREST Disclosure}

The authors declare that there is no conflict of interest statement.

\section{REFERENCES}

[1] HO SMY, Horne DJDL, Szer J. The adapation of patients during the hospitalization period of bone marrow transplantation. J Clin Psychl Med Settings. 2002; 9: 167-75. http://dx.doi.org/10.1023/A : 1014948211605

[2] Packman W, Weber S, Wallace J, et al. Psychological effects of hematopoietic SCT on pediatric patient, siblings and parents: A review. Bone Marrow Transplant. 2010; 45: 1134-46. PMid:20383219 http://dx.doi.org/10.1038/bmt.2010.74

[3] Barrera M, Atenafu E, Doyle J, et al. Differences in mothers' and fa- thers' health-related quality of life after pediatric SCT: a longitudinal study. Bone Marrow Transplant. 2012; 47(6): 855-9. PMid:21946382 http://dx.doi.org/10.1038/bmt.2011.190

[4] Terrin N, Rodday AM, Tighiouart H, et al. Journeys to Recovery Study. Parental emotional functioning declines with occurrence of clinical complications in pediatric hematopoietic stem cell transplant. Support Care Cancer. 2013; 21(3): 687-95. PMid:22936494 http://dx.doi.org/10.1007/s00520-012-1566-9

[5] Heinze KE, Rodday AM, Nolan MT, et al. The impact of pediatric blood and marrow transplant on parents: introduction of the 
parent impact scale. Health Qual Life Outcomes. 2015; 9(13): 46. PMid:25890070 http://dx.doi.org/10.1186/s12955-015-0 240-6

[6] Pentz RD, Pelletier W, Alderfer MA, et al. Shared decision-making in pediatric allogeneic blood and marrow transplantation: What if there is no decision to make? Oncologist. 2012; 17(6): 8815. PMid:22615217 http://dx.doi.org/10.1634/theoncolo gist.2011-0446

[7] Ullrich CK, Rodday AM, Bingen K, et al. Parent Outlook: How Parents View the Road Ahead as They Embark on Hematopoietic Stem Cell Transplant for Their Child. Biol Blood Marrow Transplant. 2015; Sep 5. PMid:26348891 http://dx.doi.org/10.1016/j.b bmt.2015.08.040

[8] Ginsberg JP, Hobbie WL, Carlson CA, et al. Delivering long term follow up care to pediatric cancer survivors. Transitional care issues. Pediatric Blood \& Cancer. 2006; 46: 169-173. PMid:16320315 http://dx.doi.org/10.1002/pbc. 20610

[9] Doshi K, Kazak AE, Hocking MC, et al. Why mothers accompany adolescent and young adults childhood cancer survivors to follow up clinic visits. Journal of pediatric oncology nursing. 2014; 31(1): 51-57. PMid:24451909 http://dx.doi.org/10.1177/1043454 213518111

[10] Terrin N, Rodday AM, Tighiouart H, et al. Parental emotional functioning declines with occurrence of clinical complications in pediatric hematopoietic stem cell transplant. Support Care Cancer. 2013; 21(3): 687-95. PMid:22936494 http://dx.doi.org/10.1007/s 00520-012-1566-9

[11] Sajjadi M, Rassouli M, Abbaszadeh A, et al. Lived Experiences of "Illness Uncertainty" of Iranian Cancer Patients: A Phenomenological Hermeneutic Study. Cancer Nurs. 2015; Jun 19. PMid:26098402 http://dx.doi.org/10.1097/NCC. 0000000000000282

[12] Mishel MH. Uncertainty in illness. Journal of Nursing Scholarship. 1988; 20(4): 224-232. http://dx.doi.org/10.1111/j.1547-5 069.1988.tb00082.x

[13] Mishel MH. Reconceptualization of the uncertainty in illness theory. Journal of Nursing Scholarship. 1990; 22(4): 256-262. http: //dx.doi.org/10.1111/j.1547-5069.1990.tb00225.x

[14] De Graves S, Aranda S. Living with hope and fear-the uncertainty of childhood cancer after relapse. Cancer Nursing. 2008; 31(4): 292301. PMid:18600116 http://dx.doi.org/10.1097/01. NCC.00 00305745.41582 .73

[15] Kazak AE, Alderfer M, Rourke MT, et al. Posttraumatic stress disorder (PTSD) and posttraumatic stress symptoms (PTSS) in families of adolescent childhood cancer survivors. Journal of Pediatric Psychology. 2004; 29(3): 211-219. http://dx.doi.org/10.1093/j pepsy/jsh022

[16] Norberg AL, Boman KK. Parent distress in childhood cancer: a comparative evaluation of posttraumatic stress symptoms, depression and anxiety. Acta Oncologica. 2008; 47(2): 267-274. PMid:17851875 http://dx.doi.org/10.1080/02841860701558773

[17] Manne S, DuHamel K, Ostroff J, et al. Anxiety, depressive, and posttraumatic stress disorders among mothers of pediatric survivors of hematopoietic stem cell transplantation. Pediatrics. 2004; 113(6): 1700-1708. http://dx.doi.org/10.1542/peds.113.6.1700

[18] Santacroce SJ. Parental uncertainty and posttraumatic stress in serious childhood illness. Journal of Nursing Scholarship. 2003; 35(1): 45-51. http://dx.doi.org/10.1111/j.1547-5069.2003.00045.x

[19] Santacroce S. Uncertainty, anxiety, and symptoms of posttraumatic stress in parents of children recently diagnosed with cancer. Journal of Pediatric Oncology Nursing. 2002; 19(3): 104-111. http: //dx.doi.org/10.1053/jpon.2002.123451

[20] Hansen BS, Rortveit K, Leiknes I, et al. Patient experiences of uncertainty- a synthesis to guide nursing practice and research. Journal of nursing management. 2012; 20: 266-277. PMid:22380420 http://dx.doi.org/10.1111/j.1365-2834.2011.01369.x

[21] Ring N, Jepson R, Hoskins G, et al. Understanding what helps or hinders asthma action plan use: a systematic review and synthesis of the qualitative literature. Patient Education and Counselling. 2011; 85(2): e131-43. PMid:21396793 http://dx.doi.org/10.1016 $/ \mathrm{j} \cdot$ pec. 2011.01 .025

[22] Nelson JP. Struggling to gain meaning: living with the uncertainty of breast cancer. ANS Advances in Nursing Science. 1996; 18(3): 59-76. http://dx.doi .org/10.1097/00012272-199603000-00007

[23] Burns N, Grove SK. The practice of Nursing Research 6th ed. Philadelphia: Elsevier; 2009; 124-6. PMid: 18845364

[24] Shosha GA. Employment of Colaizzi's strategy in descriptive phenomenology: a reflection of a researcher. European Scientific Journal. 2012; 8(27): 31-43.

[25] Bailey DE, Stewart JL. Mishel's theory of uncertainty in illness. In Mariner-Tomey AM, Alligood MR (Eds). Nursing theorist and their work (5 th), St. Louis, MO. 001. 560-583.

[26] Padilla GV, Mishel MH, Grant MM. Uncertainty, appraisal and quality of life. Quality of Life Research. 1992; 1(3): 155-165. PMid:1301125 http://dx.doi.org/10.1007/BF00635615

[27] Finfgeld-Connett D. Concept synthesis of the art of nursing. Journal of Advanced Nursing. 2008; 62(3): 381-388. PMid:18426463 http://dx.doi.org/10.1111/j.1365-2648.2008.04601.x 